\title{
Evaluation of Serum Levels of Vascular Endothelial Growth Factor (VEGF) in Female Patients with Telogen Effluvium
}

\author{
A.M.El-Refaey ${ }^{1}$, E.G.Behiry ${ }^{2}$, A.I.Mansour ${ }^{3}$, A.M.Hamed ${ }^{4}$ and A.A.Abd el-aziz ${ }^{5}$ \\ ${ }^{1}$ Professor of Dermatology, Venereology and Andrology Dept., Faculty of Medicine, Benha Univ., Benha, Egypt \\ ${ }^{2}$ Assistant Professor of Clinical and Chemical Pathology Dept., Faculty of Medicine, Benha Univ., Benha, Egypt \\ ${ }^{3}$ Assistant Professor of Clinical and Chemical Pathology Dept., Faculty of Medicine, Benha Univ., Benha, Egypt \\ ${ }^{4}$ Assistant Professor of Dermatology, Venereology and Andrology Dept., Faculty of Medicine, Benha Univ., Benha, Egypt \\ 5 (M.B.B.CH), Faculty of Medicine,Tanta Univ., Tanta, Egypt \\ E-Mail: dr.miro11@gmail.com
}

\begin{abstract}
Telogen effluvium is a form of non-scarring diffuse hair loss. It is characterised by premature entrance of a large number of hairs into telogen phase at one time. In recent years, many growth factors participate in the hair follicle cycle regulation and promote hair growth. Vascular endothelial growth factor (VEGF) is one of the growth factors stimulating angiogenesis and its disturbance may lead to telogen effluvium. Evaluation of serum levels of VEGF in female patients with telogen effluvium.Serum VEGF concentrations were measured in 40 consecutive women with telogen effluvium aged between 18 and 65 years in comparison with 40 women without hair loss using enzyme-linked immunosorbent assay (ELISA). Serum levels of VEGF were found to be lower in female patients than in healthy controls.Decreased serum levels of VEGF in female patients than in controls probably reflect the role of VEGF in the pathogenesis of telogen effluvium.
\end{abstract}

Keywords: Telogen effluvium, VEGF, ELISA.

\section{Introduction}

Telogen effluvium is the most common cause of diffuse hair loss in adult females. Abrupt, rapid, generalized shedding of normal club hairs occurring 2-3 months after a triggering event [1].

Many mechanisms are impeded as severe fever, pregnancy, chronic systemic diseases, horrible hemorrhage, crash diet, sudden starvation, nutritional deficiency, accidental trauma, surgical operations and severe emotional stress. TE may be acute or chronic, if hair shedding lasts less than 6 months so it is acute TE, while chronic TE is hair shedding lasting longer than 6 months [2].

Several researches highlight the role of regulatory substances in hair cycling. These include growth factor families and receptors, transcription factors, cytokines, neurotrophins, and intracellular signaling pathways [3].

Vascular endothelial growth factor (VEGF) is one of the most important growth factors that promotes angiogenesis and plays important roles in neovascularization and development of tissues [4]. VEGF and VEGFR-2 are not only expressed in normal human epidermis, but also regulate the functions of epidermal keratinocytes such as enhancing proliferation and migration of keratinocytes, decreasing the adhesion ability of keratinocytes, also the expression of VEGF has been reported in various compartments of the human hair follicle especially anagen hair follicles including outer root sheath and dermal papillae [5].

It is thought that the growth of blood vessels is associated with hair growth and thus the VEGF is involved in hair growth. VEGF has been also reported to reduce hair loss by promoting blood circulation and the formation of new blood vessels around follicles [6].

So decrease level of VEGF may play a role in the pathogenesis of telogen effluvium.

The aim of this study was to investigate the serum levels of VEGF in female patients with telogen effluvium.

\section{Material and methods}

This study was conducted as a case control study that involved 40 female patients with telogen effluvium and 40 healthy, age and sex matched controls between the age of 18 and 65 years recruited from Dermatology outpatient clinic, Benha University Hospital. All details of the study were discussed with the patients and informed consent was obtained from each patient before enrolment in the study. The protocol was revised and approved by the Ethics Committee of Human Research., Faculty of Medicine, Benha University.

Patients with any of the following conditions were excluded from the study: autoimmune

disorders, any disease that may affect VEGF serum level and pregnancy. None of the patients was on systemic or topical treatment for one month before the study .

All patients were subjected to the following:

\subsection{History taking}

Patients' demographic data were recorded: name, age and marital status. A detailed history was taken from patients regarding onset, course, duration and recurrence of hair loss. History of crash diet, significant emotional stress, major surgery, febrile illness hair dying, Straightener and any chemical procedures 2 or 3 months before hair loss was obtained. Patients were asked about easy fatigue, rapid weight gain, weight loss, sleep disorders, pregnancy and lactation. Also, patients were asked about medical problems including any systemic or skin diseases or drug intake.

\subsection{Clinical examination}

Complete general examination was done including body mass index.

Hair examination was done for assessment of hair loss distribution (diffuse or patterned), detection of any thinning or widening especially at the central part, regression or preservation of anterior hair line, patchy area of hair loss and bitemporal recession. Scalp skin examination was done 
to exclude any abnormalities like erythema, scales, infection, and epidermal changes.

Also, hair pull test was done to detect active hair shedding and confirm diagnosis of telogen effluvium. A bundle of about 50-60 hairs was grasped between the thumb, index finger, and middle finger from the base near the scalp. The hair was firmly, but not forcibly, tugged away from the scalp as fingers slide along the hair shaft. The hair was not be shampooed for at least a day. The test was considered positive when more than $10 \%$ of the grasped hair (in average more than six hairs) can be pulled out. If fewer than six hairs can be easily pulled out, this was considered normal physiologic shedding. The pull test was done in 4 scalp region: right and left parietal, frontal, and occipital region.

\subsection{Blood samples}

Blood samples were obtained and samples were allowed to clot for two hours at room temperature before centrifugation for 15 minutes at $1000 \times \mathrm{g}$. We removed serum and did assay immediately and we stored samples at $-20^{\circ} \mathrm{C}$ or $-80^{\circ} \mathrm{C}$. we avoided repeated freeze-thaw cycles. After centrifugation, serum was separated by a pipette, divided and kept in eppendorf tubes labeled with the number of the person.
This test was done using Human Vascular Endothelial Cell Growth Factor (VEGF) ELISA Kit provided by CusabiolUSA according to the manufacturer's instructions.

\subsection{Statistical Analysis}

Statistical presentation and analysis of the present study was conducted, using Statistical package for Social Science (IBM SPSS Statistics for Windows, Version 20.0. Armonk, NY: IBM Corp.).

\section{Results and discussion}

\subsection{Clinical results}

The current study was carried out on 40 female patients with telogen effluvium their ages ranged from 18 to 65 years with a mean age of $24.5 \pm 5.3$ years. The control group included 40 healthy, age-matched women. Their ages ranged from 18 to 65 years with a mean age of $25.4 \pm 6.7$ years. No statistically significant differences were found between patients and controls regarding age and BMI (Table 1). In all telogen effluvium patients, the hair pull test was positive all over the scalp (including frontal, 2 temporal and occipital regions). Also Telogen effluvium cases showed significantly higher vertex, occiput, right, left temporal, hair pull test when compared to control group Table (2).

Table (1) Comparison of age and BMI between all studied groups.

\begin{tabular}{lllllllll}
\hline & & \multicolumn{3}{l}{ Control } & \multicolumn{3}{l}{ Telogen Effluvium } & \multicolumn{2}{l}{$\mathbf{P}$} \\
& & $\mathbf{N = 4 0}$ & & $\mathbf{N = 4 0}$ & & \\
Age (years) & mean \pm SD & 25.4 & \pm & 6.7 & 24.5 & \pm & 5.3 & $0.87^{\mathrm{T}}$ \\
BMI & mean \pm SD & 26.3 & \pm & 3.5 & 26.1 & \pm & 4.4 & $0.886^{\mathrm{T}}$ \\
\hline
\end{tabular}

$\mathrm{SD}$, standard deviation; $\mathrm{T}$, $\mathrm{t}$ test.

Table (2) Comparison of hair pull test between studied groups

\begin{tabular}{|c|c|c|c|c|c|c|c|}
\hline \multirow[b]{3}{*}{ Vertex } & \multirow{2}{*}{\multicolumn{3}{|c|}{$\begin{array}{c}\begin{array}{c}\text { Control } \\
\mathrm{N}=40\end{array} \\
\text { Mean } \pm \text { SD }\end{array}$}} & \multirow{2}{*}{\multicolumn{3}{|c|}{$\begin{array}{c}\begin{array}{c}\text { Telogen Effluvium } \\
\mathbf{N}=\mathbf{5 0}\end{array} \\
\text { Mean } \pm \text { SD }\end{array}$}} & \multirow[t]{2}{*}{$\mathbf{p}$} \\
\hline & & & & & & & \\
\hline & 1.10 & \pm & 0.3 & 6.64 & \pm & 0.9 & $<0.001^{\mathrm{T}}$ \\
\hline occiput & 1.53 & \pm & 0.5 & 7.00 & \pm & 0.9 & $<0.001^{\mathrm{T}}$ \\
\hline Right temporal & 1.48 & \pm & 0.4 & 7.00 & \pm & 1.2 & $<0.001^{\mathrm{T}}$ \\
\hline Left temporal & 1.08 & \pm & 0.3 & 7.26 & \pm & 1.3 & $<0.001^{\mathrm{T}}$ \\
\hline hair pull test & 1.29 & \pm & 0.3 & 6.97 & \pm & 0.7 & $<0.001^{\mathrm{T}}$ \\
\hline
\end{tabular}

\subsection{Laboratory results}

There was a statistically significant lower in the Mean serum level of VEGF in patients than controls Table (3).

Table (3) Comparison serum VEGF concentration between all studied groups.

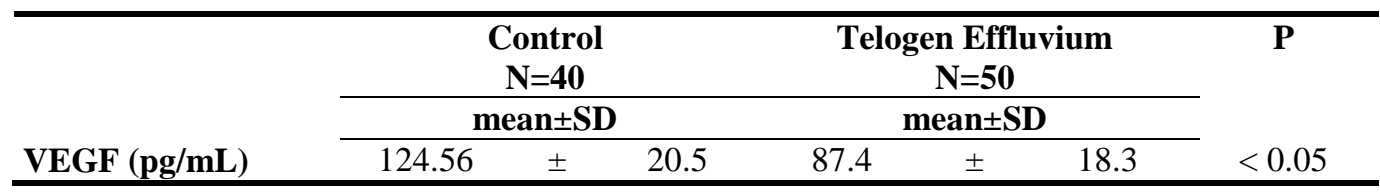

$\mathrm{SD}$, standard deviation; $\mathrm{T}, \mathrm{t}$ test. 
Telogen Effluvium is a very common and distressing disease in which sudden and diffuse hair loss is caused by normal hair growth cycle interruption due to many factors [7].

Pull test is a noninvasive diagnostic technique, very easy to perform and to repeat. It is very helpful to rapidly determine the ongoing activity and severity of any kind of hair loss. A positive test present in more than one scalp region can be seen during a telogen effluvium. The patients suffering from female patterned hair loss may have a positive pull test only during the active phases in the affected area [8].

In our study, the pull test is positive in 4 scalp regions detecting active hair shedding. This result is similar to other studies as Hodeib et al., (2017) found that the hair-pull test was positive all over the scalp (including frontal, parietal, and occipital regions) in all TE patients [9]. Also Obaidat et al., (2005) which confirm the diagnosis of chronic telogen effluvium patients with positive hair pull test [10].

On comparing both groups of patients and controls in this study, there was a significant decrease of the mean serum level of VEGF in patients than in controls.

Growth factors are capable of inducing cell proliferation of vascular endothelium and dermal fibroblasts, prolonging anagen and delaying catagen onset in a hair follicle. Hence, anagen can be prolonged and hair growth can be stimulated with the help of these growth factors [3].

Vascular endothelial growth factor plays important roles in promoting angiogenesis by stimulating capillary proliferation, migration and permeability, and by regulating the growth, differentiation and development of a variety of tissues [4].

The biological effects of VEGF are mediated by receptor tyrosine kinases. VEGFR-2, the primary receptor for VEGF, is thought to mediate most functional effects [5].

It's found that hair follicle cycling is associated with vascular remodeling [11] and the expression of VEGFR-2 changed during the hair cycle was significantly stronger during anagen II and anagen IV than during anagen VI, catagen and telogen. So this result clearly indicates that VEGFR-2 is associated with maintenance of hair cycling. Decreased expression of VEGFR-2 leads to decreased cell proliferation and increased apoptosis, causing the hair follicle to enter telogen [12].

Several studies asses the role of VEGF in hair growth as Meephansan et al. (2017) found that topical tofacitinib was effective in promoting hair growth and the possible mechanism involves increased VEGF levels and lowered inflammation. The study was done on Eight-week-old male C57BL/6 mice. They were divided equally into four groups and treated topically with tofacitinib, minoxidil, dimethyl sulfoxide and ethanol (as two controlled groups) once daily for 21 days. Tofacitinib-treated mice exhibited more rapid hair growth than either minoxidil-treated or control mice. Histopathology showed that VEGF mRNA and protein expression was significantly greater than those in the other groups with increase in the number of hair follicles, mostly in the anagen phase [13].
So, VEGF has an important functional role in hair biology, control of normal hair growth and cycling and any decrease in its level may lead to hair loss.

\section{Conclusion}

Our results showed the contribution of decreased

VEGF in the development of telogen effluvium.

\section{References}

[1] S.B. Shrivastava, Diffuse hair loss in an adult female: Approach to diagnosis and management. Indian $\mathbf{J}$ Dermatol Venereol Leprol, vol.75(1), pp.20-28, 2009.

[2] N.M. Mohammad, R.S. Ibrahium, M.H. Mohammed, S.A. Galal, R. Maher and H.A. Darwish, Etiological Role of Ferritin and Vitamin D in Patients with Telogen Effluvium. J Clin Exp Dermatol Res, vol.8(6), pp. 431-435, 2017.

[3] A.A. Kubanov, Y.A. Gallyamova and O.A. Korableva, A randomized study of biomimetic peptides efficacy and impact on the growth factors expression in the hair follicles of patients with telogen effluvium. J App Pharm Sci, vol.8(04), pp.015-022, 2018.

[4] X.Y. Man, X.H. Yang, S.Q. Cai, Z.Y. Bu, X.J. Wu and Z.F. Lu et al., Expression and localization of vascular endothelial growth factor and vascular endothelial growth factor receptor-2 in human epidermal appendages: a comparison study by immunofluorescence. Clin Exp Dermatol, vol.34(3), pp.396-401, 2009.

[5] W. Li, Z-F. Lu, X-Y. Man, C-M. Li, J. Zhou and J-Q. Chen et al, VEGF upregulates VEGF receptor-2 on human outer root sheath cells and stimulates proliferation through ERK pathway. Mol Biol Rep, vol.39, pp.8687-8694, 2012.

[6] Y.M. Woo, O.J. Kim, E.S. Jo, M.Y. Jo, M.Y. Ahn and Y-H. Lee et al., The effect of Lactobacillus plantarum hydrolysates promoting VEGF production on vascular growth and hair growth of C57BL/6 mice. J Anal Sci Technol., vol.10(1), pp.18-26, 2019.

[7] W. Hamad, A. Said and A. Abd El Hamid, Role of Some Trace Elements in the Pathogenesis of Telogen Effluvium in Egyptian Females. J Egypt Women Dermatol Soc, vol.7, pp. 44-48, 2010.

[8] A. Vujovic and V.D. Marmol, The Female Pattern Hair Loss: Review of Etiopathogenesis and Diagnosis. Biomed Res Int, vol. 2014,767628, pp.1-8, 2014.

[9] A.A. Hodeib, Y.M. El-Hamd, H.A. Mourad and R.A. Sabry, Role of iron in telogen effluvium among premenopausal women. Egypt J Dermatol Venerol., vol. 37, pp.56-61, 2017.

[10] N.A. Obaidat, B.T. Rawashdeh, A-RA. Wreikat and A.A. Awamleh, A potential relation between telogen effluvium and iron deficiency in adult females. JRMS, vol.12(1), pp. 62-66, 2005.

[11] E. Bassino, F. Gasparri, V. Giannini and L. Munaron, Paracrine crosstalk between human hair follicle dermal papilla cells and microvascular endothelial cells. Exp Dermatol., vol.24(5), pp.388-90, 2015. 
[12] X-J. Wu, J. Jing, Z-F. Lu and M. Zheng, Expression and localization of VEGFR-2 in hair follicles during induced hair growth in mice. Arch Dermatol Res., vol.310(7), pp.591-598, 2018.

[13] J. Meephansan, J. Thummakriengkrai, S. Ponnikorn, W. Yingmema, R. Deenonpoe and P. Suchonwanit,
Efficacy of topical tofacitinib in promoting hair growth in non-scarring alopecia: possible mechanism via VEGF induction. Arch Dermatol Res., vol. 309(9), pp.729-738, 2017. 